\section{Surgical Site Infections After Laparoscopic and Open Cholecystectomies in Community Hospitals}

TO THE EDITOR-Laparoscopic cholecystectomy has become the preferred method of performing gallbladder surgery over the past decade. Laparoscopic cholecystectomies are associated with shorter hospital stay and convalescence, less pain and scarring, and lower rates of postoperative surgical site infection (SSI) than open cholecystectomies. ${ }^{1-4}$ The fact that laparoscopic cholecystectomies are associated with fewer SSIs intuitively makes sense: laparoscopy access ports are short in length and only a fraction of the length of the incision used in open laparotomy. Biscione et al. ${ }^{5}$ reported in the September issue of the journal that patients who underwent laparoscopic cholecystectomy had lower rates of incisional SSI than patients who underwent open cholecystectomy; however, rates of deep incisional/organ space infections were similar in these 2 groups. ${ }^{5}$ The latter finding differs from our experience and from the results reported in the existing literature, for several reasons.

Although $80 \%$ of all cholecystectomies in the United States were performed laparoscopically in $2002,{ }^{6}$ only $59 \%$ of cholecystectomies were performed laparoscopically in the Biscione et al. study. ${ }^{5}$ Furthermore, their results showed that the use of laparoscopic cholecystectomy decreased over time, declining from $62 \%$ of procedures in 1996-1999 to $57 \%$ in 2000 and later. The authors offered no explanation for this decline. We suspect that the criteria for choosing open or laparoscopic cholecystectomy for the patients selected for this study were different from the criteria used in current practice in the United States. However, it is also possible that the higher proportion of open procedures performed in the study by Biscione et al. ${ }^{5}$ was the result of high rate of conversion from laparoscopic to open procedures as a result of technical difficulties.

The study by Biscione et al. ${ }^{5}$ was probably underpowered to assess whether the rate of deep SSI was the same or different in patients undergoing open procedures and patients undergoing laparoscopic procedures. The authors examined 5,848 procedures and observed a total of 39 deep incisional or organ space infections. In contrast, a study that showed a reduced rate of deep incisional or organ space infection following laparoscopic surgery examined 10 times that number of procedures $(54,504)$ and observed almost 7 times as many deep incisional/organ space infections (294). ${ }^{7}$

Finally, the high overall SSI rate in the study by Biscione et al. ${ }^{5}$ restricted the generalizability of their findings. Biscione et al. ${ }^{5}$ reported 3.57 infections per 100 procedures, whereas the 2004 National Nosocomial Infection Surveillance (NNIS) system data showed 3.23 infections per 100 cholecystectomies in US hospitals for patients with the highest NNIS risk index score. ${ }^{8}$ We commend Biscione et al. ${ }^{5}$ for providing valuable data on cholecystectomies in community hospitals. However, the results from the study do not appear to reflect the practice in most US hospitals.

We analyzed data collected by the Duke Infection Control Outreach Network on the rate of SSI following cholecystectomy to determine whether our findings were the same or dissimilar to those reported by Biscione et al. ${ }^{5}$ Data on the risk of SSI were prospectively collected from 38,232 patients who underwent cholecystectomy in 31 community hospitals in the southeastern United States during the period from 1991 to 2007. The median size of the participating hospitals was 220 beds (range, 39-537 beds). We determined the rates of SSI for laparoscopic and open cholecystectomies and then stratified the rates by age, NNIS risk index score, American Society of Anesthesiologists classification, wound class, and the year that surgery was performed. Hypothesis testing was performed with the $\chi^{2}$ test for categorical variables, 2 -tailed $P$ values, and an $\alpha$ of .05 .

A total of 145 SSIs were identified following 38,232 cholecystectomies (ie, 0.38 infections per 100 procedures) during the 15 -year study period (Table); 35,316 (94\%) of these cholecystectomies were performed laparoscopically. The median patient age was 49 years. Open cholecystectomy was performed more often for older patients: the proportion of patients older than 60 years of age was $47 \%$ in the open cholecystectomy group and $29 \%$ in the laparoscopic cholecystectomy group $(P<.001)$. Open cholecystectomy was performed more often during the 1990s than it was after 2000: from 1991 to 2000 , a total of $75 \%$ of cholecystectomies were performed laparoscopically; $94 \%$ of all procedures were done laparoscopically after $2000(P<.001)$.

The SSI rate was 1.37 infections per 100 open cholecystectomies and 0.30 infections per 100 laparoscopic procedures (relative rate ratio, 4.61 [95\% confidence interval, 4.29-4.97]; $P<.001)$. We also performed subgroup analyses after stratifying the data by NNIS risk index score, age (older than 60 years), American Society of Anesthesiologists classification, wound class, surgical duration (more than 120 minutes or 120 minutes or less), and the year in which the operation was performed (before or after 2000). Laparoscopic cholecystectomies consistently had lower rates of SSI, compared with open procedures in all subgroups; with significant $P$ values for each analysis, except for one comparison (Table). The type of surgery (laparoscopic or open) remained significantly associated with SSI in a multivariable model that controlled for all significant variables in the univariate analysis.

For the reasons cited above, we think that it is unwise to generalize the findings reported by Biscione et al. ${ }^{5}$ to patients 
TABLE Rates and Relative Rate Ratios for Surgical Site Infection (SSI) Following Open and Laparoscopic Cholecystectomies in a Cohort of 38,232 Patients from 31 Community Hospitals

\begin{tabular}{|c|c|c|c|c|c|c|}
\hline \multirow[b]{2}{*}{ Variable } & \multicolumn{2}{|c|}{$\begin{array}{l}\text { Open procedure } \\
(n=2,916)\end{array}$} & \multicolumn{2}{|c|}{$\begin{array}{l}\text { Laparoscopic procedure } \\
\qquad(n=35,316)\end{array}$} & \multirow{2}{*}{$\begin{array}{l}\text { Relative rate ratio } \\
(95 \% \mathrm{CI})\end{array}$} & \multirow[b]{2}{*}{$P$} \\
\hline & SSIs/procedures ${ }^{a}$ & SSI rate ${ }^{\mathrm{b}}$ & SSIs/procedures ${ }^{\mathrm{a}}$ & SSI rate ${ }^{b}$ & & \\
\hline Overall & $40 / 2,916$ & 1.37 & $105 / 35,316$ & 0.30 & $4.61(3.21-6.62)$ & $<.001$ \\
\hline \multicolumn{7}{|c|}{ Patient characteristic } \\
\hline \multicolumn{7}{|c|}{ NNIS risk index score } \\
\hline 0 & $6 / 1,067$ & 0.56 & $44 / 22,926$ & 0.19 & $2.93(1.25-6.86)$ & $<.001$ \\
\hline 1 & $15 / 1,357$ & 1.11 & $49 / 11,087$ & 0.44 & $2.50(1.41-4.45)$ & $<.001$ \\
\hline$\geqslant 2$ & $19 / 492$ & 3.86 & $12 / 1,303$ & 0.92 & $4.19(2.05-8.57)$ & $<.001$ \\
\hline \multicolumn{7}{|l|}{ Age } \\
\hline$\leqslant 60$ years & $12 / 1,551$ & 0.77 & $54 / 25,052$ & 0.22 & $3.59(1.92-6.70)$ & $<.001$ \\
\hline$>60$ years & $28 / 1,365$ & 2.05 & $51 / 10,264$ & 0.50 & $4.12(2.61-6.52)$ & $<.001$ \\
\hline \multicolumn{7}{|c|}{ ASA classification } \\
\hline$<3$ & $14 / 1,585$ & 0.88 & $52 / 24,820$ & 0.21 & $4.21(2.34-7.59)$ & $<.001$ \\
\hline$\geqslant 3$ & $25 / 1,331$ & 1.95 & $53 / 10,496$ & 0.50 & $3.87(2.42-6.16)$ & $<.001$ \\
\hline \multicolumn{7}{|l|}{ Surgical duration } \\
\hline$\leqslant 120$ minutes & $20 / 2,069$ & 0.97 & $91 / 33,107$ & 0.27 & $3.52(2.17-5.69)$ & $<.001$ \\
\hline$>120$ minutes & $20 / 847$ & 2.36 & $14 / 2,209$ & 0.63 & $3.73(1.89-7.34)$ & $<.001$ \\
\hline \multicolumn{7}{|l|}{ Wound class } \\
\hline CL-CC & $32 / 2,762$ & 1.16 & $100 / 34,444$ & 0.29 & $3.99(2.69-5.93)$ & $<.001$ \\
\hline $\mathrm{CO}-\mathrm{I}$ & $8 / 154$ & 5.19 & $5 / 872$ & 0.57 & $9.06(3-27.3)$ & $<.001$ \\
\hline \multicolumn{7}{|l|}{ Time of surgery } \\
\hline Before 2000 & $6 / 894$ & 0.67 & $10 / 2,648$ & 0.38 & $1.78(0.65-4.88)$ & .26 \\
\hline After 2000 & $34 / 2,022$ & 1.68 & $95 / 32,668$ & 0.29 & $5.78(3.92-8.53)$ & $<.001$ \\
\hline
\end{tabular}

Note. ASA, American Society of Anesthesiologists physical status; CC, clean contaminated; CL, clean; CO, contaminated; I, infected; NNIS, National Nosocomial Infection Surveillance system.

" No. of SSIs / no. of procedures.

${ }^{b}$ No. of infections per 100 procedures.

in the United States. In fact, it may not be possible to use data on the risk of SSI following cholecystectomy that were collected prior to 2000 to assess the risk of SSI for patients undergoing this procedure now. Finally, because in modern practice the majority of open cholecystectomies have been converted from attempted laproscopic procedures immediately after they are determined to have been unsuccessful, the risk of complications following open cholecystectomy is likely to be quite different than was observed in the recent past (eg, prior to 2000). However, our review of the risk of SSI in a cohort of 38,232 patients who underwent cholecystectomy supports the findings of other investigators who have concluded that laparoscopic cholecystectomy is associated with significantly lower rate of SSI, compared with open procedures. ${ }^{3,7,9,10}$

Luke F. Chen, MBBS (Hons), FRACP; Deverick J. Anderson, MD, MPH; Matthew G. Hartwig, MD; Keith S. Kaye, MD, MPH; Daniel J. Sexton, MD

From the Division of Infectious Diseases, Duke Infection Control Outreach Network (L.F.C., D.J.A., K.S.K., D.J.S.), and the Department of Surgery (M.G.H.), Duke University Medical Center, Durham, North Carolina.
Address reprint requests to Luke F. Chen, MBBS, FRACP, 2100 Erwin Road, Durham, NC, 27710 (luke.chen@duke.edu).

Infect Control Hosp Epidemiol 2008; 29:92-94

(C) 2007 by The Society for Healthcare Epidemiology of America. All rights reserved. 0899-823X/2008/2901-0019\$15.00.DOI: 10.1086/524335

\section{REFERENCES}

1. Legorreta AP, Silber JH, Costantino GN, Kobylinski RW, Zatz SL. Increased cholecystectomy rate after the introduction of laparoscopic cholecystectomy. JAMA 1993; 270:1429-1432.

2. Hendolin HI, Paakonen ME, Alhava EM, Tarvainen R, Kemppinen T, Lahtinen P. Laparoscopic or open cholecystectomy: a prospective randomised trial to compare postoperative pain, pulmonary function, and stress response. Eur J Surg 2000; 166:394-399.

3. Zacks SL, Sandler RS, Rutledge R, Brown RS Jr. A population-based cohort study comparing laparoscopic cholecystectomy and open cholecystectomy. Am J Gastroenterol 2002; 97:334-340.

4. Inoue $\mathrm{H}$, Itoh $\mathrm{K}-\mathrm{i}$, Hori $\mathrm{H}$, et al. The cosmetic benefit of three-port laparoscopic cholecystectomy and umbilical trocar insertion. Dig Endosc 1994; 6:49-51.

5. Biscione FM, Couto RC, Pedrosa TM, Neto MC. Comparison of the risk of surgical site infection after laparoscopic cholecystectomy and open cholecystectomy. Infect Control Hosp Epidemiol 2007; 28:1103-1106.

6. Livingston $\mathbf{E H}$, Rege RV. A nationwide study of conversion from laparoscopic to open cholecystectomy. Am I Surg 2004; 188:205-211.

7. Richards C, Edwards J, Culver D, Emori TG, Tolson J, Gaynes R. Does using a laparoscopic approach to cholecystectomy decrease the risk of surgical site infection? Ann Surg 2003; 237:358-362.

8. National Nosocomial Infections Surveillance (NNIS) System Report, data 
summary from January 1992 through June 2004, issued October 2004 Am J Infect Control 2004; 32:470-485.

9. Chuang SC, Lee KT, Chang WT, et al. Risk factors for wound infection after cholecystectomy. $J$ Formos Med Assoc 2004; 103:607-612.

10. Williams LF, Jr., Chapman WC, Bonau RA, McGee EC, Jr., Boyd RW, Jacobs JK. Comparison of laparoscopic cholecystectomy with open cholecystectomy in a single center. Am J Surg 1993; 165:459-465.

\section{Reply to Chen et al.}

T O THE EDITOR-We really appreciate the interest of Dr. Chen and colleagues ${ }^{1}$ in our recent article. ${ }^{2}$ Several factors may explain the lower rate of laparoscopic cholecystectomy in our institutions. It is not the consequence of higher rates of conversion to open cholecystectomy, because we kept converted procedures in their original surgical group. First, note that our institutions adopted the National Nosocomial Infection Surveillance (NNIS) system's definition of operative procedure, which excludes outpatient (same-day) surgical procedures. ${ }^{3}$ Thus, same-day laparoscopic cholecystectomies were excluded from the analysis, lowering the overall proportion of laparoscopic procedures. Furthermore, our increasing use of same-day laparoscopic cholecystectomy in recent years, similar to increases in the use of this procedure elsewhere around the world, can account for the apparent reduction in the proportion of laparoscopic cholecystectomy observed in our series over time. Second, the use of miniincision cholecystectomy as an alternative approach to both open cholecystectomy and laparoscopic cholecystectomy is rising in frequency in our country. For surveillance purposes, we consider classic laparotomic cholecystectomies and miniincision cholecystectomies to be open cholecystectomies. So, inclusion of data on procedures with mini-incision access would lower the rate of laparoscopic cholecystectomy but leave the rate of open cholecystectomy unchanged.

Third, recall that our institutions are private and not university affiliated, and major differences exist in clinical practices in comparison to public or university-affiliated hospitals. Although economic concerns are obviously not unique to the private sector, the economic pressures exerted by health plans assume a clear role in private institutions, particularly in a resource-constrained country such as ours. Economic evaluations conducted in developed countries have so far favored laparoscopic cholecystectomy over open cholecystectomy, but the cost savings of laparoscopic cholecystectomy may be less apparent in other types of institutions ${ }^{4}$ or when compared with minilaparotomy cholecystectomy. ${ }^{5}$ Moreover, some ways in which laparoscopic cholecystectomy has demonstrated clear superiority over open cholecystectomy, such as shorter associated sick leave, do not necessarily represent a clear benefit to health plans and, accordingly, do not enter in their cost-effectiveness equations. More importantly, even with the assumption that laparoscopic cholecystectomy is cost effective, laparoscopic cholecystectomy savings may not overcome the increased consumption of healthcare resources resulting from the well-known rise in the number of cholecystectomies performed and in hospital use after laparoscopic cholecystectomy is introduced. ${ }^{6-8}$ It is possible that all of these concerns may have limited the availability of laparoscopy in our institutions to some extent.

That our study might have been underpowered to detect a lower risk of organ space infections after laparoscopic cholecystectomy was acknowledged in the Discussion section of our article. ${ }^{2}$ Chen et al. ${ }^{1}$ declined to assess the risk of organ space infection in their study, so the assertion that our finding differs from their experience is not supported by their data. It is misleading to consider the study by Richards et al. ${ }^{9}$ as valid evidence of reduced risk of organ space infection following laparoscopic cholecystectomy. The lower crude rate of organ space infection after laparoscopic cholecystectomy reported in that study was an unadjusted comparison and, therefore, was not mentioned as a major finding by the authors. ${ }^{9}$ In that study, patients who underwent laparoscopic cholecystectomy were obviously less prone to infection than patients who underwent open cholecystectomy, because laparoscopic cholecystectomies were shorter in duration, and patients who underwent these procedures were younger and less likely to have an American Society of Anesthesiologists classification of 3 or greater, dirty or contaminated wounds, emergency procedures, or multiple procedures performed through the same incision. ${ }^{9}$ Therefore, laparoscopic cholecystectomy and open cholecystectomy could not be straightforwardly compared without a multivariate analysis, which was only provided for the overall risk of surgical site infection (SSI). ${ }^{9}$ We still believe that, if our extensive cohort of 5,848 patients failed to show a difference in the risk of organ space infection, a potential difference seems to be clinically irrelevant in our setting.

Chen et al.' should note that more caution in needed when comparing the SSI rates we reported ${ }^{2}$ with those of the NNIS system. The most obvious reason for the higher SSI rate in our cohort was the higher proportion of open cholecystectomies. Second, the NNIS system emphasizes that, for SSI rate comparisons to be valid, it must be known whether case finding included infections detected after discharge and the postdischarge surveillance method must be the same ${ }^{10}$; however, their own reports repeatedly fail to declare whether postdischarge surveillance was actually used and what proportion of patients were reached by postdischarge surveillance. ${ }^{11}$ Chen et al. ${ }^{1}$ also did not mention whether postdischarge surveillance was used in their study. Therefore, any comparison between their SSI rates and ours is irrelevant, and inferences about the generalizability of our data based on such comparisons are hasty and inaccurate. In our study, 55.5\% of all SSIs were detected after discharge, even though a modest $49.5 \%$ of patients were reached by postdischarge surveillance. ${ }^{2}$ In the study by Richards et al., ${ }^{9}$ only $28.8 \%$ of SSIs were 